\title{
EFFECT OF WATER-SAVING TECHNOLOGIES ON GROWTH, YIELD, AND WATER-SAVING POTENTIAL OF LOWLAND RICE
}

\author{
Hayat Ullah $^{1 *}$, Avishek Datta ${ }^{1}$ \\ ${ }^{1}$ Department of Food, Agriculture, and Bioresources, School of Environment, Resources, and \\ Development, Asian Institute of Technology, Pathum Thani 12120, Thailand
}

(Received: February 2018 / Revised: February 2018 / Accepted: November 2018)

\begin{abstract}
Alternative methods of rice production that use fewer freshwater inputs are crucial for sustainable rice production in the context of decreasing irrigation water availability, which may further exacerbate due to climate change. The direct seeding (DS) method of cultivation (either dry or wet) and alternate wetting and drying (AWD) are among such ways, which could contribute to decreasing irrigation water inputs in rice production without a considerable yield penalty, thus increasing water productivity. The objective of the study was to investigate the performance of a popular, lowland, Thai rice variety (Pathumthani 1) under different cultivation methods subjected to different threshold levels of AWD. The treatments involved three cultivation methods (dry direct seeding [DDS], wet direct seeding [WDS], and transplanting [TP]) and four soil moisture levels of $0,-5,-15$, and $-30 \mathrm{kPa}$, maintained through a permanently installed tensiometer. The growth, yield components, grain yield, and water-saving potential of rice under different cultivation methods and soil moisture levels were determined. There were more unfilled grains at $-30 \mathrm{kPa}$ under the DDS method. At the severe moisture stress of $-30 \mathrm{kPa}$, the DDS method resulted in a $24 \%$ higher grain yield than did the TP method, whereas the difference in grain yield between WDS and TP was nonsignificant at moisture levels of $0,-15$, and $-30 \mathrm{kPa}$. The highest water-saving potential of $62 \%$ compared with the traditional continuous flooding method was observed at $-30 \mathrm{kPa}$, which was reduced by $24-82 \%$ for the other soil moisture levels. The performance of Pathumthani 1 was better under the DDS method at all soil moisture levels. The threshold level of AWD could be -30 $\mathrm{kPa}$ for soil and weather conditions comparable to the present study for its high water productivity compared with yield reduction.
\end{abstract}

Keywords: Alternate wetting and drying; Continuous flooding; Dry direct seeding; Water productivity; Wet direct seeding

\section{INTRODUCTION}

Freshwater resources around the world are consistently declining, leading toward competition for this precious natural resource. Agricultural water availability is steadily decreasing for various reasons, including competition among different economic sectors, reduced investment in irrigation infrastructure, water quality deterioration due to pollution, and alarming population growth (Rijsberman, 2006; Datta et al., 2017). In most of the Asian countries, per capita availability of water declined by 40-60\% between 1955 and 1990 and is projected to decline further by 15-54\% over the next 35 years (Gleick, 1993). Agricultural production needs to be

\footnotetext{
*Corresponding author's email: hayatbotanist204@gmail.com, Tel. 0066-94-296-9486 Permalink/DOI: https://doi.org/10.14716/ijtech.v9i7.1666
} 
doubled in the twenty-first century to feed the growing world population in the context of decreasing water availability for agricultural purposes (Foley et al., 2011). It is, therefore, necessary to find alternative methods with fewer water inputs for agricultural purposes in order to maintain productivity and sustainability. Rice (Oryza sativa L.) is the main staple food crop for almost one-third of the global population who are mostly poor, and thus it is critically important to global food security (Ullah et al., 2018). Rice is not an exclusive hydrophyte, but its cultivation under inundated conditions has been in practice for a long time. On average, rice production requires double the amount of water for each unit of production than for that of any other cereal crop (Maclean et al., 2002). A total of 93 million ha of irrigated lowland area provides $75 \%$ of the world's rice production, and increasing water scarcity can threaten the sustainability of its production. A considerable amount of water is lost from rice fields during land preparation and the crop-growth period through unproductive evaporation, seepage, and percolation flows (Bouman \& Tuong, 2001). Therefore, wastage of freshwater in the rice field needs to be minimized because more irrigated land is devoted to rice production than to any other crop in the world (IRRI, 2003). Rice is a primary source of caloric intake for most Asian people. Most of the Asian countries face severe challenges of rapid population growth, widespread poverty, and vulnerability of its major rice-producing areas to climate change. By $2025,15-20$ million ha of irrigated rice land is projected to suffer from some degree of water scarcity (Tuong \& Bouman, 2003). Therefore, it is of the utmost importance to identify alternative methods by which more food can be produced with less water, given the projected increase in freshwater scarcity for irrigated agriculture and the rising demand of food in the coming future.

The water-use efficiency of rice is very low in the Asian region, especially for small farmers, who could contribute $75 \%$ of rice production in the coming decade. The yield gap in this region is very high, and there is a general belief that this gap could be narrowed through the efficient use of resources and increased water-use efficiency of rice. For this reason, a number of rice production management strategies have been developed, some of which are closely related. Among these techniques, the most common are alternate wetting and drying (AWD) (Belder et al., 2004), integrated crop management, aerobic rice culture (Bouman \& Tuong, 2001), use of controlled-release fertilizers (Shoji \& Kanno, 1994), and the system of rice intensification (SRI) (Stoop et al., 2002). DS is also an important strategy for efficient water management. This technique is very useful in reducing water loss during land preparation. Because rice is a high water-demanding crop, a slight decrease in water input for its cultivation would save huge amounts of freshwater, which could be used for other economic sectors, or would allow further areas to be brought under cultivation. A major shift has been observed in Asia toward adopting the DS method of cultivation due to increasing water scarcity and high labor wages (Datta et al., 2017; Ullah et al., 2017). Farmers in areas with sufficient irrigation water and labor availability practice the traditional transplanting cultivation method, in which fields remain flooded for most of the growing period, but farmers in areas with shortages of water and labor generally prefer water-saving cultivation techniques. The dire predictions for 2025 indicate a serious water shortage problem for irrigated rice cultivation in most of the rice-growing areas, including Thailand. On the other hand, most of the popularly grown rice varieties are cultivated under lowland conditions, and evaluation of the performance of such varieties under watersaving cultivation techniques is critically important. Therefore, the present study was designed to evaluate the performance of a popularly grown rice variety, Pathumthani 1, under different cultivation methods and thresholds of AWD water regime. 


\section{MATERIALS AND METHODS}

The experiments were conducted in a polyhouse at the Asian Institute of Technology, Bangkok, Thailand (latitude $14^{\circ} 01^{\prime} 12^{\prime \prime} \mathrm{N}$, longitude $100^{\circ} 31^{\prime} 12^{\prime \prime} \mathrm{E}$ ) during the rice-growing season of 2016-2017. The experiments were laid out in a completely randomized design with four replications. Plants were grown in a naturally lit polyhouse in which the temperature fluctuated between 30 and $35^{\circ} \mathrm{C}$. Seeds of the Pathumthani 1 rice variety were collected from the Pathum Thani Rice Research Center, Pathum Thani, Thailand.

Seeds were sown on nursery trays for the transplanting method. Dry seeds were directly sown into the dry soil in each pot for the DDS, whereas pre-germinated seeds were sown in the puddled soil in the WDS method. Seedlings were transplanted into the pots at the rate of three seedlings pot $^{-1}$ when they attained the age of 15 days, which was later thinned to one seedling pot $^{-1}$ after establishment. The experimental soil was moderately acidic, with a pH of 5.4 (Table 1) and was classified as a clay loam soil (sand $29.0 \%$, silt $40.9 \%$, and clay $30.1 \%$ ) according to the USDA Soil Classification System. It was adequate in phosphorus $(\mathrm{P})$, potassium $(\mathrm{K})$, and organic matter but was deficient in total nitrogen $(\mathrm{N})$. A total of 48 pots $(27 \mathrm{~cm}$ height with 14 $\mathrm{cm}$ top and $9 \mathrm{~cm}$ bottom diameter) were used for this study. The study consisted of one rice variety (Pathumthani 1), three cultivation methods (dry direct seeding [DDS], wet direct seeding [WDS], and transplanting [TP]), and four soil water potentials $(0,-5,-15$, and -30 $\mathrm{kPa}$ ). Soil water potential was monitored by a permanently installed tensiometer (Model 2725ARL Jet Fill Tensiometer, Soilmoisture Equipment Corp., CA, USA). Each pot was filled with $6.5 \mathrm{~kg}$ of soil. NPK (16-16-16) was applied at a rate of $0.7 \mathrm{~g} \mathrm{pot}^{-1}$ as basal, and urea (46-00 ) was top dressed in two splits at maximum tillering and panicle initiation stages.

Table 1 Physiochemical properties of the experimental soil

\begin{tabular}{lc}
\hline \multicolumn{1}{c}{ Parameters } & Test Results \\
\hline $\mathrm{pH}$ & 5.40 \\
Organic matter & $1.9 \%$ \\
Total nitrogen & $<0.50 \mathrm{~g} \mathrm{l}^{-100 \mathrm{~g} \mathrm{~g}^{-1}}$ \\
Available phosphorus & $90.27 \mathrm{mg} \mathrm{kg}^{-1}$ \\
Exchangeable potassium & $452.39 \mathrm{mg} \mathrm{kg}^{-1}$ \\
Exchangeable calcium & $0.39 \mathrm{~g} \mathrm{100} \mathrm{g}^{-1}$ \\
Exchangeable magnesium & $436.59 \mathrm{mg} \mathrm{kg}^{-1}$ \\
\hline
\end{tabular}

\subsection{Data Collection}

Data on the different growth parameters, yield components, grain yield, and water-saving potential of the different methods were collected at harvest (124 days after sowing). Water saving was calculated from the total amount of water applied to the different treatments compared with the total water applied to continuously flooded pots.

\subsection{Data Analysis}

The experiment was conducted twice. The data represent the average of the two experiments because there was no time by treatment interaction. Data were analyzed using the analysis of variance (ANOVA) function of IRRISTAT 5.0 (IRRI, 2005). Means for significant treatment effects were separated by Fisher's protected least significant difference (LSD) test at $p<0.05$. The treatment combination means presented for a variable are based on the highest order of factorial combination that is significant in the ANOVA. 


\section{RESULTS AND DISCUSSION}

The two-way interaction between cultivation method and soil moisture regime was significant $(p<0.05)$ for number of productive tillers plant ${ }^{-1}$ (Figure 1$)$. The DDS method produced a higher number of productive tillers irrespective of soil moisture regimes, whereas TP produced the lowest number of productive tillers across all soil moisture regimes. At $0 \mathrm{kPa}$, DDS had a significantly higher number of productive tillers plant ${ }^{-1}$ (25) compared with WDS (22) and TP (17). The highest difference was observed at $-5 \mathrm{kPa}$, where the number of productive tillers for DDS was $38 \%$ and $71 \%$ higher than for WDS and TP, respectively, and where WDS had $24 \%$ more than TP. DDS achieved the highest number of productive tillers at $-5 \mathrm{kPa}$, which was $8 \%$, $12 \%$, and $23 \%$ more than productive tillers at $0,-15$ and $-30 \mathrm{kPa}$, respectively. The number of productive tillers under WDS and TP were not affected by the decreasing soil moisture regime.

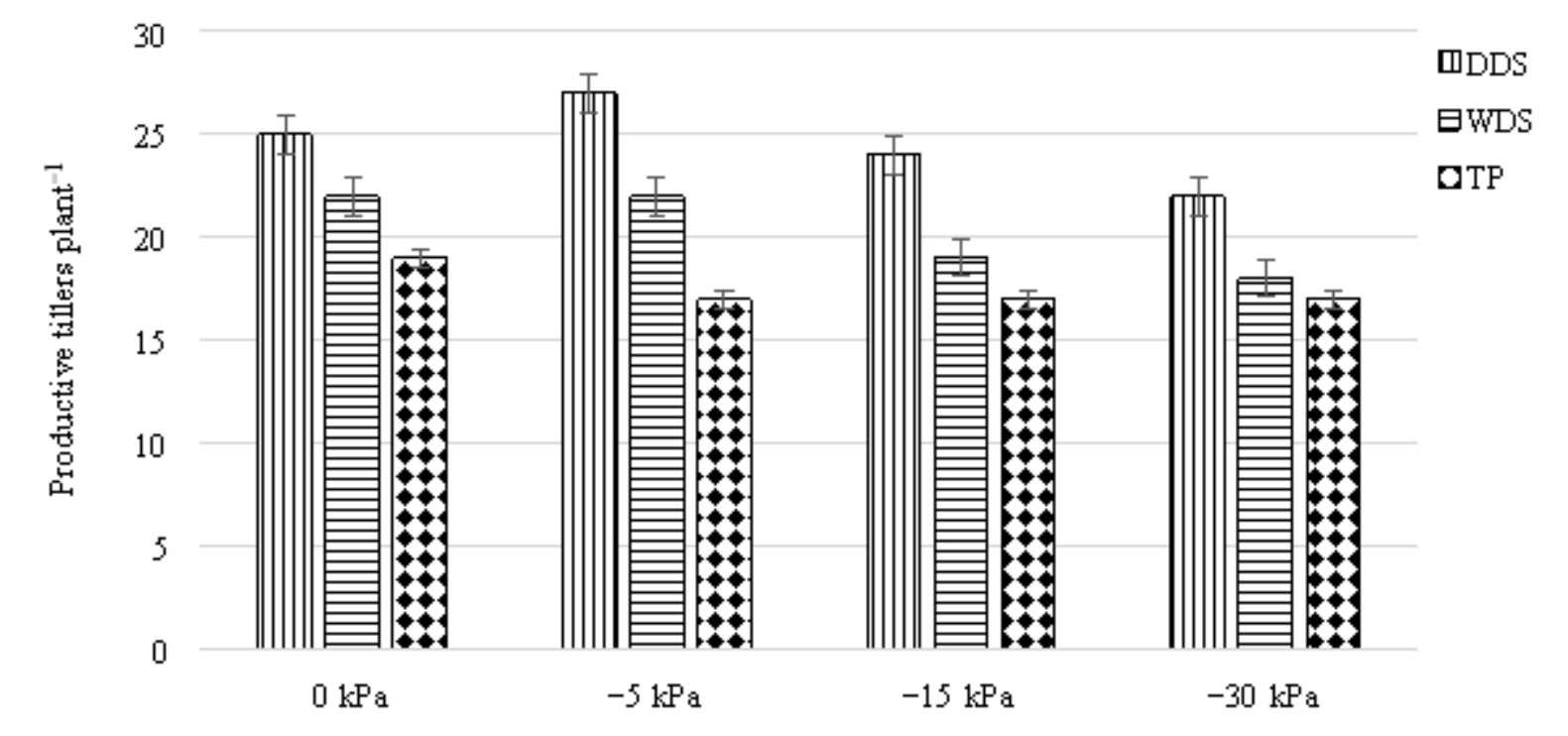

Figure 1 Number of productive tillers plant ${ }^{-1}$ of Pathumthani 1 rice variety as affected by cultivation method and soil moisture regime. DDS: Dry Direct Seeding; WDS: Wet Direct Seeding; TP:

Transplanting; kPa: Kilopascal; Bars with the same letters are not significantly different at $p<0.05$

The number of unfilled grains panicle ${ }^{-1}$ was highly significantly $(p<0.01)$ affected by the twoway interaction between cultivation method and soil moisture regime (Figure 2). More unfilled grains were observed under DDS at 0 (36) and $-30 \mathrm{kPa}(46)$, which was statistically at par with WDS and $80 \%$ higher than TP at $0 \mathrm{kPa}$, and $28 \%$ and $31 \%$ higher than WDS and TP, respectively, at $-30 \mathrm{kPa}$. All cultivation methods had a statistically similar number of unfilled grains at -5 and $-15 \mathrm{kPa}$. DDS had the highest number of unfilled grains at $-30 \mathrm{kPa}(46)$, which was $28 \%, 100 \%$, and $130 \%$ higher than unfilled grains at $0,-5$, and $-15 \mathrm{kPa}$, respectively. The highest number of unfilled grains panicle ${ }^{-1}$ under WDS was observed at -30 $\mathrm{kPa}$, which was statistically at par with $0 \mathrm{kPa}$, but $57 \%$ and $71 \%$ higher than unfilled grains panicle $^{-1}$ at -5 and $-15 \mathrm{kPa}$, respectively. There were $75 \%, 40 \%$, and $46 \%$ more unfilled grains panicle $^{-1}$ at $-30 \mathrm{kPa}$ under TP compared with $0,-5$, and $-15 \mathrm{kPa}$, respectively.

The 1000-grain weight was significantly $(p<0.05)$ affected by the two-way interaction between cultivation method and soil moisture regime (Figure 3). No significant difference was observed among the three cultivation methods at $0 \mathrm{kPa}$, and the same was also true for DDS and WDS across all soil moisture regimes. At -5 and $-15 \mathrm{kPa}$, DDS and WDS had $11 \%$ and $14 \%$ higher 1000-grain weights, respectively, than did TP. At $-30 \mathrm{kPa}$, WDS had a 14\% higher 1000-grain weight than did TP. The effect of decreasing soil moisture on 1000-grain weight under DDS 
and WDS was not significant up to $-15 \mathrm{kPa}$, but the severe moisture stress of $-30 \mathrm{kPa}$ caused a reduction of $25 \%, 23 \%$, and $23 \%$ in 1000 -grain weight compared with $0,-5$, and $-15 \mathrm{kPa}$ under DDS, and 20\%, 22\%, and 22\% under WDS, respectively. The highest 1000-grain weight under TP was observed at $0 \mathrm{kPa}$, which was reduced by $10 \%, 10 \%$, and $29 \%$ at $-5,-15$, and $-30 \mathrm{kPa}$, respectively.

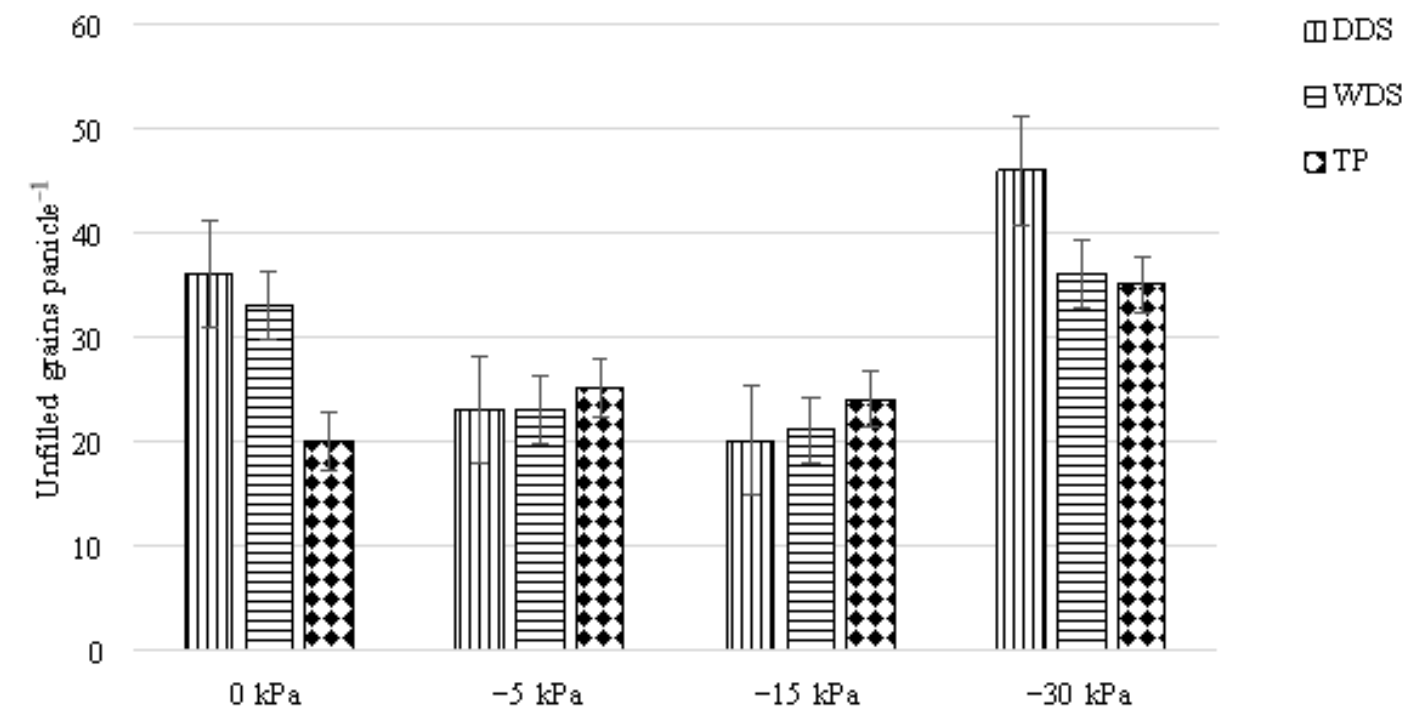

Figure 2 Unfilled grains panicle ${ }^{-1}$ of Pathumthani 1 rice variety as affected by cultivation method and soil moisture regime. DDS: Dry Direct Seeding; WDS: Wet Direct Seeding; TP: Transplanting; kPa:

Kilopascal; Bars with the same letters are not significantly different at $p<0.05$

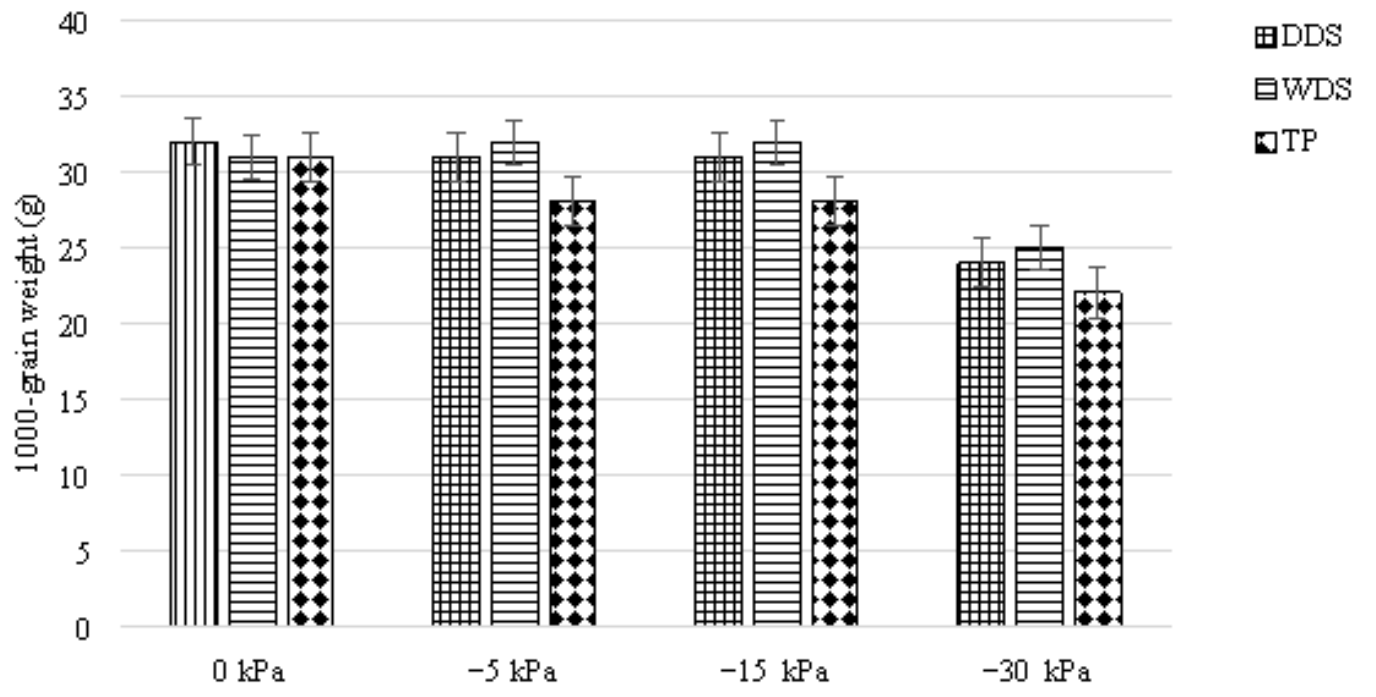

Figure 3 The 1000-grain weight (G) of Pathumthani 1 rice variety as affected by cultivation method and soil moisture regime. DDS: Dry Direct Seeding; WDS: Wet Direct Seeding; TP: Transplanting; kpP:

Kilopascal; Bars with the same letters are not significantly different at $p<0.05$

Grain yield was significantly $(p<0.05)$ affected by the two-way interaction between cultivation method and soil moisture regime (Figure 4). A higher grain yield was evident under DDS across all soil moisture regimes. At $0 \mathrm{kPa}$, DDS had a $17 \%$ higher grain yield than did TP, while the difference at $-5,-15$, and $-30 \mathrm{kPa}$ was $51 \%, 39 \%$, and $24 \%$, respectively. WDS and TP had statistically similar grain yields at $0,-15$, and $-30 \mathrm{kPa}$; however, WDS had a $29 \%$ higher grain yield than did TP at $-5 \mathrm{kPa}$. Declining soil moisture decreased grain yield across 
all cultivation methods, but DDS had the highest grain yield at $-5 \mathrm{kPa}$, which was statistically similar with 0 and $-15 \mathrm{kPa}$, but $30 \%$ higher than grain yield at $-30 \mathrm{kPa}$. Grain yield under WDS was statistically similar up to $-15 \mathrm{kPa}$, but the severe moisture stress of $-30 \mathrm{kPa}$ caused a $17 \%$ reduction in grain yield compared with $-5 \mathrm{kPa}$. Increasing moisture stress caused a grain yield reduction of $23 \%, 23 \%$, and $28 \%$ at $-5,-15$, and $-30 \mathrm{kPa}$, respectively, compared with 0 $\mathrm{kPa}$ under TP.

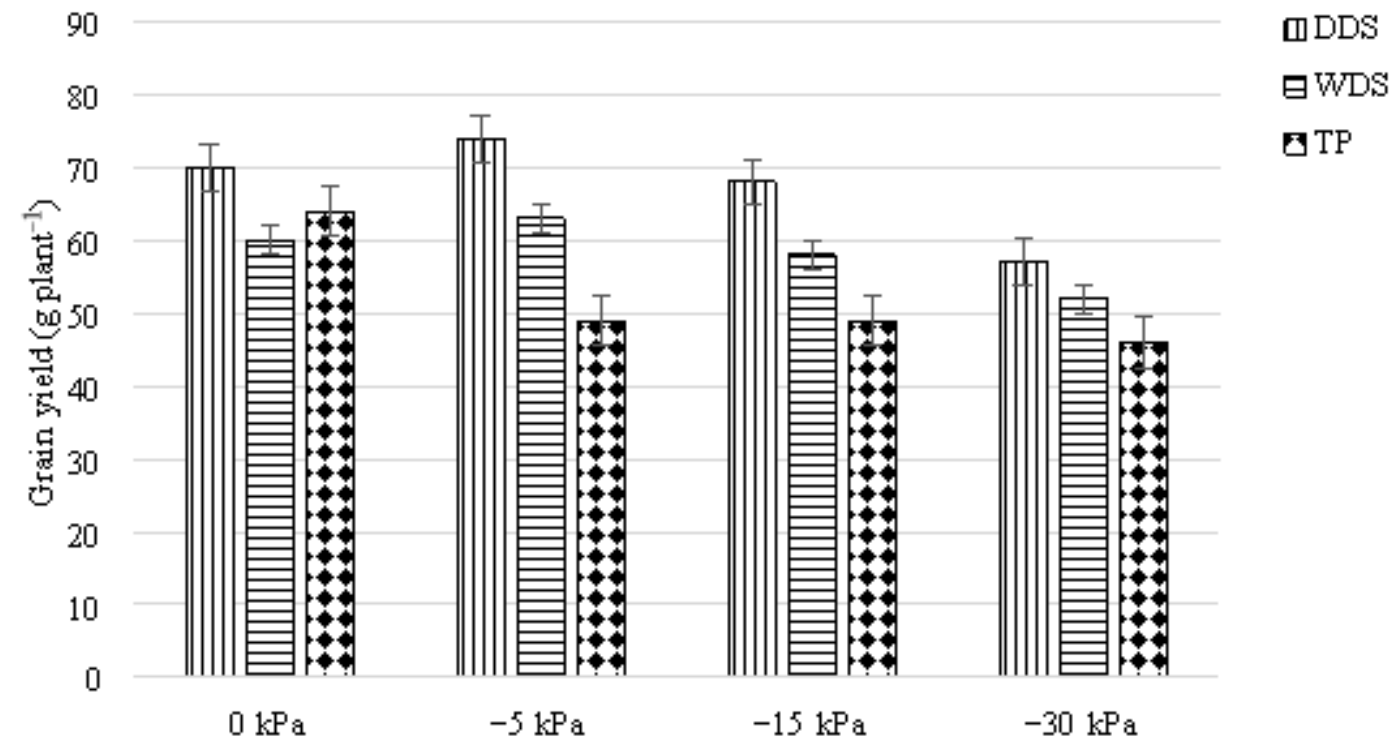

Figure 4 Grain yield $\left(\mathrm{g} \mathrm{plant}^{-1}\right.$ ) of Pathumthani 1 rice variety as affected by cultivation method and soil moisture regime. DDS, Dry Direct Seeding; WDS, Wet Direct Seeding; TP, Transplanting; kPa,

Kilopascal; Bars with the Same Letters are Not Significantly Different at $p<0.05$

A significant difference was observed among the different soil moisture regimes for watersaving potential compared with the traditional continuous flooding method (Figure 5). The soil moisture regime of $0 \mathrm{kPa}$, in which the soil was kept moist without standing water, resulted in a water saving of up to $12 \%$ compared with continuous flooding conditions, while $-5,-15$, and $-30 \mathrm{kPa}$ saved $38 \%, 47 \%$, and $62 \%$ more water, respectively, compared with flooded conditions.

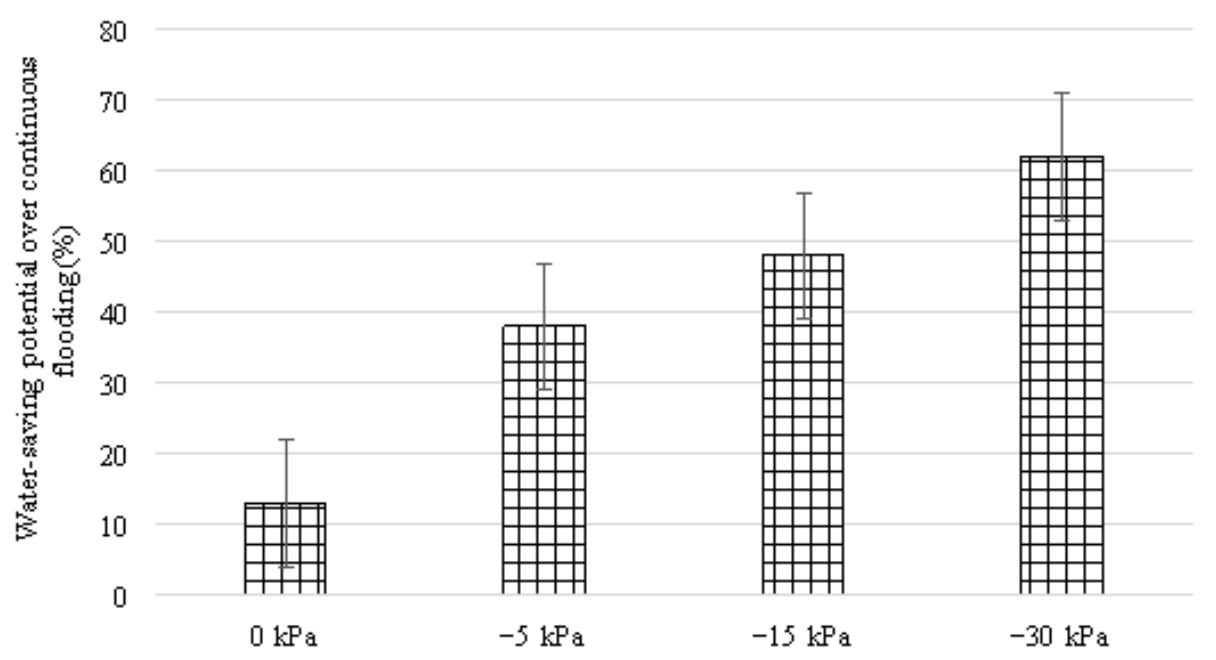

Figure 5 Water-saving potential of different soil moisture regimes over continuous flooding method. $\mathrm{kPa}$ : Kilopascal; Bars with the same letters are not significantly different at $p<0.05$ 
AWD is a water-efficient technology to cope with increasing water scarcity for agricultural purposes, especially for irrigated rice (Datta et al., 2017). Under this system, water $(\sim 2-5 \mathrm{~cm})$ is applied to the field at an interval of 2-7 days, depending on soil type and environmental conditions, after the disappearance of ponded water from the soil surface (Tuong \& Bouman, 2003). Proper use of this technology can help save up to $40 \%$ of water and lead to an indirect increase in farmers' income through reduced expenses in water pumping and fuels (Lampayan et al., 2015). We observed that this technique could be safely applied up to a threshold level of $-30 \mathrm{kPa}$ with some yield penalty (Figure 4). DDS in increasingly becoming popular due to the low labor and water inputs (Ullah et al., 2017), and a major shift has been observed from the traditional TP to the DDS method in recent years in many parts of Asia (Ullah et al., 2017). The major reasons for this shift include: (i) decreasing water availability for irrigation; (ii) labor shortages and increased wages; (iii) recent developments in DS technology; (iv) adverse effects of puddling on soil physiochemical properties and other non-rice crops; and (v) growing interest in conservation agriculture (Kumar \& Ladha, 2011). The better results observed under DDS during the present study are in close agreement with the findings of Kumar and Ladha (2011). We observed more unfilled grains in decreasing soil moisture regimes, a finding similar to that of Datta et al. (2017), who mentioned that a greater number of unfilled grains is a typical symptom of water-deficit stress in rice. The current results are also in close agreement with Zubaer et al. (2007), who reported a higher number of unfilled grains with reduced soil moisture levels. Hossain (2001) observed more unfilled grains panicle ${ }^{-1}$ with decreasing soil moisture levels. Yambao and Ingram (1988) also reported increased sterility percentage with water stress during the reproductive stage. Begum (1990) observed an increased number of empty spikelets with water stress after flowering. Our results for the 1000-grain weight are similar to those of RRDI (1999), who also reported decreased grain weight of rice under water stress during the grain-filling stage. Begum (1990) observed decreased individual grain weight with water stress after the flowering stage. Tsuda and Takami (1991) mentioned reduced grain weight under water stress. Zubaer et al. (2007) reported decreased 1000-grain weight with reduced soil moisture levels. Islam et al. (1994) also observed reduced 1000-grain weight due to water stress. For soils comparable to the present study, a possible maximum limit for safe AWD could be $-30 \mathrm{kPa}$ without a considerable loss in grain yield but with a high water-saving potential. Reduced water input and high water productivity are usually credited to reduced seepage and percolation (Cabangon et al., 2004), along with reduced evapotranspiration. However, seepage and percolation are strongly linked with soil texture, and the rates are higher for lighter soils than for heavy soils (Sharma, 1989). Thus, the optimum threshold should be site specific to obtain the maximum benefits from AWD, primarily depending on soil type and texture.

\section{CONCLUSION}

A water-saving cultivation method (DDS or WDS) could be safely recommended for the tested rice variety under soil and weather conditions comparable to the present study. Pathumthani 1 performed better under DDS in all soil moisture regimes and could be adopted as a watersaving cultivation technique. Application of different soil moisture regimes helped save significant amounts of water compared with traditional flooding conditions, albeit with some yield penalty. The threshold AWD level of $-30 \mathrm{kPa}$ could be recommended, resulting in some degree of yield loss but with a high water-saving potential for soil and weather conditions comparable to the present study. Evaluation of the current study under field conditions is recommended to validate the experimental findings. 


\section{ACKNOWLEDGEMENT}

The authors thank the Higher Education Commission, Pakistan, and the Asian Institute of Technology, Thailand, for providing financial assistance with a scholarship to the first author for graduate studies at the Asian Institute of Technology, Thailand.

\section{REFERENCES}

Begum, F.A., 1990. Effect of Different Levels of Light and Drought Stress on Individual Spikelet Filling in Rice (Oryza sativa L.). Thesis, University of Philippines, College, Laguna, Philippines

Belder, P., Bouman, B.A.M., Cabangon, R., Guoan, L., Quilang, E.J.P., Yuanhua, L., Spiertz, J.H.J., Tuong, T.P., 2004. Effect of Water-saving Irrigation on Rice Yield and Water Use in Typical Lowland Conditions in Asia. Agricultural Water Management, Volume 65(3), pp. 193-210

Bouman, B.A.M., Tuong, T.P., 2001. Field Water Management to Save Water and Increase Its Productivity in Irrigated Lowland Rice. Agricultural Water Management, Volume 49(1), pp. 11-30

Cabangon, R.J., Tuong, T.P., Castillo, E.G., Bao, L.X., Lu, G., Wang, G., Cui, Y., Bouman, B.A.M., Li, Y., Chen, C., Wang, J., 2004. Effect of Irrigation Method and N-fertilizer Management on Rice Yield, Water Productivity and Nutrient-use Efficiencies in Typical Lowland Rice Conditions in China. Paddy Water Environment, Volume 2(4), pp. 195-206

Datta, A., Ullah, H., Ferdous, Z., 2017. Water Management in Rice. In: Rice Production Worldwide, Chauhan, B.S., Jabran, K., Mahajan, G. (eds.), Springer, Dordrecht, the Netherlands, pp. 255-277

Foley, J.A., Ramankutty, N., Brauman, K.A., Cassidy, E.S., Gerber, J.S., Johnston, M., Mueller, N.D., O’Connell, C., Ray, D.K., West, P.C., Balzer, C., Bennett, E.M., Carpenter, S.R., Hill, J., Monfreda, C., Polasky, S., Rockström, J., Sheehan, J., Siebert, S., Tilman, D., Zaks, D.P.M., 2011. Solutions for a Cultivated Planet. Nature, Volume 478, pp. 337-342

Gleick, P.H. (ed.), 1993. Water in Crisis: A Guide to the World's Fresh Water Resources. Oxford University Press, New York.

Hossain, M.A., 2001. Growth and Yield Performance of Some Boro Rice Cultivars under Different Soil Moisture Regimes. Thesis, Department of Crop Botany, Bangladesh Agriculture University, Mymensingh, Bangladesh

Islam, M.T., Islam, M.T., Salam, M.A., 1994. Growth and Yield Performance of Some Rice Genotypes under Different Soil Moisture Regimes. Bangladesh Journal of Training and Development, Volume 7(2), pp. 57-62

International Rice Research Institute (IRRI), 2003. Annual Report. International Rice Research Institute, Los Banos, Laguna, Philippines, pp. 125-131

International Rice Research Institute (IRRI), 2005. IRRISTAT for Windows: A Statistical Package for Analysis of Data. International Rice Research Institute, Manila

Kumar, V., Ladha, J.K., 2011. Direct Seeding of Rice: Recent Developments and Future Research Needs. Advances in Agronomy, Volume 111, pp. 297-413

Lampayan, R.M., Rejesus, R.M., Singleton, G.R., Bouman, B.A.M., 2015. Adoption and Economics of Alternate Wetting and Drying Water Management for Irrigated Lowland Rice. Field Crops Research, Volume 170, pp. 95-108

Maclean, J.L., Dawe D.C., Hardy, B., Hettel, G.P. (eds.), 2002. Rice Almanac. International Rice Research Institute (IRRI), Los Banos (Philippines)

Rijsberman, F.R., 2006. Water Scarcity: Fact or Fiction? Agricultural Water Management, Volume 80(1-3), pp. 5-22 
Rice Research and Development Institute (RRDI), 1999. Netscape-Effect of Water Deficit. Department of Agriculture, Batalagoda, Ibbagamuwa, Sri Lanka

Sharma, P.K., 1989. Effect of Periodic Moisture Stress on Water-use Efficiency in Wetland Rice. Oryza, Volume 26, pp. 252-257

Shoji, S., Kanno, H., 1994. Use of Polyolefin-coated Fertilizers for Increasing Fertilizer Efficiency and Reducing Nitrate Leaching and Nitrous Oxide Emissions. Fertilizer Research, Volume 39(2), pp. 147-152

Stoop, W.A., Uphoff, N., Kassam, A., 2002. A Review of Agricultural Research Issues Raised by the System of Rice Intensification (SRI) from Madagascar: Opportunities for Improving Farming Systems for Resource-poor Farmers. Agricultural Systems, Volume 71(3), pp. 249-274

Tsuda, M., Takami, S., 1991. Changing in Heading Date and Panicle Weight in Rice Subjected to Water Stress During the Early Stage of Panicle Development. Japanese Journal of Crop Sciences, Volume 60, pp. 241-246

Tuong, T.P., Bouman, B.A.M., 2003. Rice Production in Water Scarce Environments. In: Water Productivity in Agriculture: Limits and Opportunities for Improvement. Kijne, J.W., Barker, R., Molden, D. (eds.), CABI Publishing, Wallingford, UK, pp. 53-67

Ullah, H., Datta, A., Shrestha, S., Ud Din, S., 2017. The Effects of Cultivation Methods and Water Regimes on Root Systems of Drought-tolerant (RD6) and Drought-sensitive (RD10) Rice Varieties of Thailand. Archives of Agronomy and Soil Sciences, Volume 63(9), pp. 1198-1209

Ullah, H., Luc, P.D., Gautam, A., Datta, A., 2018. Growth, Yield and Silicon Uptake of Rice (Oryza sativa) as Influenced by Dose and Timing of Silicon Application under Waterdeficit Stress. Archives of Agronomy and Soil Science, Volume 64(3), pp. 318-330

Yambao, E.B., Ingram, K.T., 1988. Drought Stress Index for Rice. Philippines Journal of Crop Sciences, Volume 13(2), pp. 105-111

Zubaer, M.A., Chowdhury, A.K.M.M.B., Islam, M.Z., Ahmed, T., Hasan, M.A., 2007. Effects of Water Stress on Growth and Yield Attributes of Aman Rice Genotypes. International Journal of Sustainable Crop Production, Volume 2(6), pp. 25-30 